\title{
Transposition
}

Musique et Sciences Sociales

$4 \mid 2014$

Musique et conflits armés après 1945

\section{Un bruit lointain ? Les musiciens chiliens face à la Guerre du Vietnam (1965-1975)}

A distant noise? Chilean musicians confronting the Vietnam War (1965-1975)

\section{Mauricio Gómez Gálvez}

\section{(2) OpenEdition}

\section{Journals}

Édition électronique

URL : http://journals.openedition.org/transposition/584

DOI : 10.4000/transposition.584

ISSN : 2110-6134

Éditeur

CRAL - Centre de recherche sur les arts et le langage

Référence électronique

Mauricio Gómez Gálvez, « Un bruit lointain ? Les musiciens chiliens face à la Guerre du

Vietnam (1965-1975) », Transposition [En ligne], 4 | 2014, mis en ligne le 15 juillet 2014, consulté le 19 avril 2019. URL : http://journals.openedition.org/transposition/584 ; DOI : 10.4000/transposition.584

Ce document a été généré automatiquement le 19 avril 2019

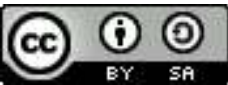

La revue Transposition est mise à disposition selon les termes de la Licence Creative Commons Attribution - Partage dans les Mêmes Conditions 4.0 International. 


\title{
Un bruit lointain? Les musiciens chiliens face à la Guerre du Vietnam (1965-1975)
}

A distant noise? Chilean musicians confronting the Vietnam War (1965-1975)

\author{
Mauricio Gómez Gálvez
}

\section{NOTE DE L'AUTEUR}

Le titre fait allusion à l'article de presse de l'historien chilien FERMANDOIS, Joaquín, "Chile y la Guerra de Vietnam. Ruido a la distancia », in La Tercera, 23 avril 2000. L'article de Fermandois entend minimiser rétrospectivement l'impact de la Guerre du Vietnam au Chili, en considérant que ce conflit armé «n'a pas eu d'influence perceptible dans le pays ». Si cela est certes valable pour une partie importante de la population, l'examen de la documentation de l'époque, y compris les registres des mobilisations citoyennes et surtout l'importante production artistique suscitée par ce conflit armé, relativise considérablement les affirmations de cet auteur. Plus qu'une réfutation, notre article se veut une contribution à un débat historiographique - même s'il a lieu « à distance »-, en jetant un nouveau regard sur un aspect encore peu étudié - celui de la réception de la Guerre du Vietnam - pendant une période particulièrement controversée de l'histoire politique et culturelle chilienne.

1 Si les mouvements d'opposition à la Guerre du Vietnam nés en Europe et aux États-Unis sont aujourd'hui assez connus, ceux apparus en Amérique latine demeurent peu étudiés. Tout comme dans les pays du nord, la jeunesse étudiante et nombre d'artistes d'Amérique du sud jouent un rôle actif dans la lutte contre un conflit armé perçu comme injuste, et condamnent l'intervention nord-américaine au nom de l'anti-impérialisme. Au Chili, les artistes, et tout particulièrement les musiciens, se mobilisent pour soutenir la lutte vietnamienne et blâmer l'envahisseur yanqui. 
Bien que certains musiciens savants ${ }^{1}$ réagissent en composant des œuvres à cette fin, c'est dans le domaine de la chanson que le rejet de la guerre trouvera une plus forte résonance sociale. En effet, les chansons de musiciens tels que Víctor Jara ou du groupe Quilapayún jalonnent une période cruciale pour le pays, marquée par la quête d'une "voie chilienne au socialisme». Ces artistes engagés appartiennent à ce qui sera bientôt nommé la Nouvelle Chanson Chilienne ${ }^{2}$ (désormais NCCh), mouvement musical rénovateur, en phase avec le climat politique à caractère révolutionnaire qui se répand dans le continent latino-américain. Le Vietnam, tout comme la Révolution cubaine, sera chanté en tant qu'étendard de la lutte contre l'impérialisme ${ }^{3}$.

La plupart des artistes - y compris les musiciens - convergeront vers le projet politique de Salvador Allende à la tête de l'Unité populaire, le soutenant activement lors de la campagne présidentielle qui le conduira au pouvoir en 1970. Sur le plan international, cet événement projettera le Chili au cœur de l'affrontement idéologique entre les deux superpuissances mondiales. Nous partons de l'hypothèse que la lutte contre la Guerre du Vietnam, en tant que facteur majeur de mobilisation et de cohésion sociale, a joué un rôle important dans l'éclosion de formes d'art politiquement engagé $e^{4}$ y compris la musique, consolidant - et préfigurant parfois - les manifestations les plus caractéristiques de la période de l'Unité Populaire. Dans quelle mesure le combat contre la Guerre du Vietnam a-t-il contribué à définir les formes d'expression de l'engagement des musiciens chiliens ?

\section{Devenir d'une contestation : de la classe politique à la société civile et aux artistes}

4 Au moment où éclate la Guerre du Vietnam, le Chili entre dans une période de profondes transformations politiques et sociales. En septembre 1964, le démocrate-chrétien Eduardo Frei Montalva, brandissant le slogan de "Révolution dans la liberté ", était élu Président de la République. Le programme du gouvernement annonçait des mesures de fond telles que la nationalisation du cuivre (première étape d'un processus qui sera approfondi pendant le gouvernement d'Allende) et une réforme agraire. Frei, fortement appuyé par les États-Unis, incarnait une sorte d'alternative viable face à une droite transitoirement épuisée, mais aussi un frein aux avancées des forces de gauche, qui menaçaient les intérêts de l'oligarchie locale et des capitaux étrangers dans le pays. Malgré son relatif progressisme, le gouvernement de Frei s'affaiblira rapidement, en perdant le soutien d'une bonne partie de ses électeurs. Il s'agit d'un moment clé de l'histoire chilienne qui voit alors culminer des mouvements sociaux, et où la jeunesse - ouvrière et universitaire - joue un rôle prépondérant. Cette période est en effet celle de l'émergence d'une génération contestataire qui se distinguera des générations précédentes en raison d'un fort engagement éthique, la conduisant à adopter une nouvelle attitude de rébellion permanente, à l'instar des révolutionnaires cubains et des résistants vietnamiens ${ }^{5}$. La force de cette génération se reflète dans le processus de Réforme universitaire qui démocratisera l'université chilienne et l'ouvrira au plus grand nombre. Au moment où la figure des héros révolutionnaires tels que Che Guevara alimente l'imaginaire d'une jeunesse avide de changements radicaux, plusieurs mouvements prônant la voie armée surgissent au Chili, notamment le MIR (Mouvement de la gauche révolutionnaire), fondé en 1965. Si ces groupes semblent incarner à bien des égards l'air du temps, attirant effectivement une partie de la jeunesse contestataire, celle-ci ne rompra pas avec les structures politiques traditionnelles dominantes (Parti communiste, Parti socialiste, etc.), 
mais elle tendra à créer des organismes politiques conciliant l'action directe et l'action représentative ${ }^{6}$. C'est le cas du MAPU (Mouvement d'action populaire unitaire), scission de l'aile radicale du Parti démocrate-chrétien en 1969. Si le dilemme entre la voie pacifique et la voie armée pour conquérir le socialisme au Chili est l'objet de débats animés, la nécessité de soutenir solidairement le combat vietnamien est unanime au sein de la jeunesse engagée de gauche.

\section{Le refus de la guerre}

5 L'une des premières manifestations de condamnation de la guerre dans le Sud-Est asiatique a lieu au Congrès national le 7 avril 1965: le sénateur du Parti communiste chilien Carlos Contreras y prononce un long discours à propos de l'intervention nordaméricaine au Vietnam 7 . En 1966, le relais est pris par diverses associations qui se regroupent pour créer le Comité chilien de solidarité avec le Vietnam. Cet organisme fait circuler un tract intitulé " Dehors les yankees du Vietnam $!^{8}$ ». Le texte, " appel au peuple du Chili », s'attaquait violemment à l'impérialisme nord-américain.

6 Au mois de janvier de la même année, la revue d'orientation révolutionnaire Punto Final (elle était en effet proche du MIR), publiait un numéro spécial sous le titre «Ce que j’ai vu au Vietnam ». Il s'agissait d'un long reportage du jeune avocat et journaliste chilien José Rodríguez Elizondo, témoignant de sa visite à la République Démocratique du Vietnam, en tant que délégué de l'Association internationale des juristes démocrates ${ }^{9}$. Au Chili, Punto Final sera le porte-parole des demandes du FLN et du gouvernement de la RDVN ${ }^{10}$, comme en attestent plusieurs communiqués. Cette revue a joué un rôle actif dans la prise de conscience collective des enjeux de la guerre.

7 Au-delà de ces actions politiques, nous ne pouvons pas négliger le fait que l'impact de la guerre sur la population sera également tributaire de la culture de masse et de ses moyens de diffusion, notamment de la télévision. Si elle entre tardivement dans les foyers, le déroulement de la Coupe du Monde de football au Chili en 1962 avait déclenché l'achat de nombre d'appareils dans le pays ${ }^{11}$. Les images de la guerre s'installaient désormais dans le quotidien de la population, ce qui modifiait considérablement le rapport des citoyens à la réalité mondiale, nourrissant ainsi l'imaginaire d'une jeunesse en révolte.

\section{La réponse des artistes}

8 Les réactions des artistes chiliens ne se font pas attendre. Ainsi, depuis l'étranger, le peintre surréaliste Roberto Matta conçoit un tableau en grand format intitulé de façon allusive Burn, Baby, Burn (1965-1966). Rappelant le Guernica de Picasso, le tableau dénonce à la fois les horreurs de la Guerre du Vietnam et les émeutes ayant eu lieu dans le quartier de Watts à Los Angeles en août $1965^{12}$. Dans le pays, l'Association chilienne des écrivains organise, en octobre 1967, un concours de poésie afin de rendre « Hommage au peuple vietnamien ». Un volume collectif est publié à l'issue de cet événement, sous le titre de Vietnam héroïque (1967). D'après le texte de présentation, le récital poétique, tenu en octobre de la même année, rassemble un public aussi fervent que nombreux. Outre l'explication de l'engagement suscité chez les écrivains, le texte souligne l'importance symbolique et concrète de la Guerre du Vietnam pour un pays comme le Chili : 
...le peuple vietnamien ne lutte pas seulement contre l'impérialisme nordaméricain; sa lutte implique la défense de la libre détermination des peuples, le respect des petits pays, et de la dignité de tous les êtres humains, sans considérer la couleur de leur peau. Sa victoire sera la victoire des peuples opprimés par la bourgeoisie impérialiste internationale. Ce sera la fin de l'esclavage économique qui domine l'Amérique latine, et elle ouvrira les portes pour que l'humanité marche en liberté, en paix et avec dignité ${ }^{13}$.

9 La guerre suscite également la réaction des plus grands poètes chiliens. Le premier semble avoir été Pablo de Rokha, qui déjà dans les années 1950 fustigeait la France, dont les soldats « dopés à la benzédrine et à l'alcool se suicident/ dans les colonies par les mitrailleuses du Vietnam/ tels des cochons affolés ${ }^{14}$ ». Pour sa part, Nicanor Parra, l'«antipoète", dans le registre d'ironie anarchisante et de détournement qui le caractérisent, écrira en 1970 un court poème en anglais :

My Stomach

maybe in this country

but

my

heart

is

in

Vietnam ${ }^{15}$

Pourtant, c'est la contribution du poète Pablo Neruda qui aura le plus de retentissements, dépassant largement le champ littéraire. Dès la fin des années 1930, à l'époque de son engagement dans la Guerre civile espagnole en faveur de la $\mathrm{II}^{\mathrm{e}}$ République, Neruda était devenu une référence incontournable. Le tournant politique de son œuvre fait bientôt de lui le paradigme d'un artiste engagé. Son œuvre, profondément ancré dans l'histoire du continent latino-américain (par exemple son Chant général, publié en 1950), incarne alors pour beaucoup la preuve d'une alliance réussie entre art et politique, entre conduite éthique et exigence esthétique. L'influence nérudienne a été déterminante pour les musiciens, comme l'affirme le compositeur Fernando García: «La figure militante du poète a aidé nombre de musiciens chiliens à mieux comprendre le rôle que le créateur doit jouer dans notre continent au moment où la lutte anti-impérialiste s'intensifie ${ }^{16}$ ». La dernière période de la poésie nérudienne est marquée par la référence à la Guerre du Vietnam $^{17}$. En 1969, l'Académie Américaine et l'Institut National des Arts et Lettres élisent Neruda membre honoraire. Renouvelant son engagement, le poète chilien accepte cette distinction, mais refuse la remise de l'insigne et du diplôme des mains de l'ambassadeur des États-Unis au Chili, au nom de la solidarité avec le Vietnam et en soutien à la protestation du monde intellectuel nord-américain à l'égard de la guerre ${ }^{18}$.

\section{Les musiciens pour le Vietnam}

11 La première œuvre musicale faisant allusion à la guerre appartient à un compositeur de musique savante : il s'agit de Por la justicia y la Paz (Pour la justice et la paix), cycle de deux 
chansons pour ténor et piano sur des textes de Paul Éluard, composé en 1965 par Eduardo Maturana. L'œuvre est dédiée "À la mémoire des tombés pour la guerre du Vietnam ${ }^{19}$ ". Elle sera suivie par Dialexsis (1966), œuvre instrumentale du compositeur Gabriel Brncic, qui sera créée à Buenos Aires ${ }^{20}$.

Dans le domaine de la musique populaire, l'un des premiers chants qui évoque explicitement le Vietnam, c'est l'hymne du MIR, intitulé "Trabajadores al poder " (Travailleurs au pouvoir) ${ }^{21}$. Quelques vers notamment montrent l'importance symbolique que représentait la lutte vietnamienne pour les groupes révolutionnaires: «Depuis le tréfonds du peuple a surgi/ une voix de justice sociale/ Ce sont les pauvres du monde qui avancent/ comme exemple ils ont le Vietnam ${ }^{22}$ ». En 1967, un disque du chanteur Rolando Alarcón incluait deux chansons à visées pacifistes : « No juegues a ser soldado » (Ne joue pas à être soldat) et «La balada de Abraham Lincoln» (La ballade d'Abraham Lincoln) ${ }^{23}$. Ces chansons ne constituaient pourtant qu'un premier pas de la transition artistique d'Alarcón vers la chanson engagée.

C'est durant l'année 1968 que la musique populaire rejoint sans ambages la contestation contre la guerre. Et ce sont les musiciens de la NCCh qui prennent le devant de la scène. Ce mouvement musical est né par réaction à la puissante pénétration culturelle nordaméricaine, à l'instar des figures tutélaires telles que la chilienne Violeta Parra ou l'argentin Atahualpa Yupanqui. Le mouvement s'est articulé graduellement grâce à la confluence esthétique et idéologique de ses membres, dont la plupart - tout en partant des recherches sur le folklore - évolueront vers une création originale marquée par les changements politiques du continent. Les musiciens de la NCCh rompent avec la conception étroite du folklore national, incarnée entre autres par les groupes de la musique dite typique chilienne (de forte inspiration patronale), en s'appropriant des instruments et des rythmes de tout le continent latino-américain : attitude esthétique et politique lourde de sens, signifiant l'internationalisme de leur démarche artistique.

Si une partie de la production musicale de la NCCh est tolérée par les multinationales du disque présentes dans le pays, la radicalisation politique du mouvement à partir de 1968 exigera la création d'outils de diffusion alternatifs. Ainsi, les jeunesses communistes créent le label Jota Jota ${ }^{24}$, sous lequel paraît le disque X Vietnam (Pour le Vietnam) du groupe Quilapayún. C'est la contribution chilienne au IX Festival mondial de la jeunesse et des étudiants, organisé à Sofia, en Bulgarie, et consacré cette année-là au Vietnam ${ }^{25}$. L'album réunit un répertoire de chansons politiques dont la première ${ }^{26}$, la seule originale du groupe, lançait au rythme de rin $^{27}$ un avertissement à l'envahisseur nord-américain : "Yankee, yankee, yankee/ Attention, attention/ (...) Aigle noir bientôt tu tomberas ${ }^{28}$ ".

$15 X$ Vietnam sera un succès de ventes et devra être réédité à plusieurs reprises, malgré l'impossibilité d'être diffusé à la radio ${ }^{29}$, celle-ci étant contrôlée majoritairement - de façon directe ou indirecte - par l'oligarchie chilienne et les trust étrangers ${ }^{30}$, hostiles à l'orientation idéologique de ces musiciens. Ce disque marque un tournant dans la carrière de Quilapayún en raison d'un répertoire nettement engagé, véhiculant une conception internationaliste qui dépasse largement le cadre latino-américain. En effet, on y retrouve des chansons du répertoire politique espagnol, italien, cubain et chilien. Ce positionnement aura une grande influence sur les réalisations à venir. 


\section{L'intensification du combat artistique}

16 L'année 1969 est particulièrement mouvementée. À l'instar de Quilapayún, d'autres musiciens expriment alors leur engagement pour le Vietnam en composant de nouvelles chansons ou en s'appropriant le répertoire étranger. Ángel Parra publie en 1969 un disque intitulé Canciones funcionales (Chansons fonctionnelles) où il s'en prend aux banquiers, à la bourgeoisie, à la répression sous le gouvernement de Frei, à l'interventionnisme étranger par le biais des ambassades (notamment celle des ÉtatsUnis) et à l'invasion culturelle nord-américaine. Prenant pour cible les détenteurs du capital, Parra ironise sur la cause de leurs malheurs, tout en faisant allusion à la guerre dans le Sud-Est asiatique et à la guerre civile au Nigeria : « Il souffre le banquier/ combien de peines aura-t-il/ Serait-ce le Vietnam, serait-ce le Biafra/ qui le font pleurer ${ }^{31}$ ? ».

Le chanteur Rolando Alarcón publie deux albums faisant tous deux explicitement référence au Vietnam: Por Cuba y Vietnam et El mundo folklórico de Rolando Alarcón. Le premier disque, comme son nom l'indique, est entièrement consacré à chanter les gestes des peuples cubain et vietnamien. La nouveauté de ces disques est l'incorporation de chansons issues du répertoire folk anglais (Ewan MacColl) et nord-américain (Pete Seeger) en traduction espagnole. Il reprend notamment une chanson de MacColl contre la guerre («Brother, did you weep?»), sous le titre de "Hermano, hermano...llorarás » (Frère, frère...tu pleureras $)^{32}$.

Les passerelles avec l'art contestataire nord-américain sont également présentes dans l'œuvre du chanteur, acteur et metteur en scène Víctor Jara, l'une des figures phares de la NCCh. Il inclut d'abord une chanson de Pete Seeger dans son disque Pongo en tus manos abiertas (Je mets dans tes paumes ouvertes) de 1969, puis adapte, dans le domaine théâtral - en lien avec la guerre -, Viet Rock de Megan Terry. Loin d'offrir une reprise littérale de cette pièce, Jara a soumis le texte à un traitement extrêmement critique, en raison de certains désaccords idéologiques avec l'auteure nord-américaine. Jara s'en est lui-même expliqué :

L'auteure ne dépasse pas le pacifisme nord-américain primaire. Elle ne voit pas l'impérialisme de son pays avec la même vision que les chiliens et les latinoaméricains [...] La position que j'ai prise face à cette œuvre est celle du jugement et de la condamnation de l'impérialisme. Nous ne sommes pas nord-américains et nous n'avons pas de raison de tomber dans les distorsions de l'auteure. Il y a des nord-américains qui sous une apparence progressiste n'arrivent pas à se libérer d'une vision tordue - et dans le fond impérialiste - du Tiers-monde ${ }^{33}$.

\section{0 km contre l'impérialisme...}

Sur le plan de la mobilisation citoyenne contre la guerre, l'événement marquant de l'année est la Marche pour le Vietnam qui a lieu entre Valparaíso et Santiago du 6 au 11 septembre $1969^{34}$. Des milliers d'étudiants et travailleurs de gauche, voire des jeunesses démocrates-chrétiennes, participent à cette manifestation. D’après les témoignages, les manifestants interviennent dans chaque petite ville afin d'exposer les motifs de la mobilisation, gagnant ainsi des sympathisants qui rejoignent le cortège. Un groupe de muralistes placé en avant-garde est chargé de peindre des fresques, en y inscrivant des slogans contre la guerre et l'impérialisme yanqui. Cet événement marque la première action publique du mouvement muraliste chilien (notamment des Brigadas Ramona 
Parra ${ }^{35}$. Un modeste mais néanmoins important documentaire a été filmé par les cinéastes Claudio Sapiaín et Álvaro Ramírez. Produit par le Centre d'étudiants de l'Institut Pédagogique de l'Université du Chili, ce film en noir et blanc emprunte son nom à l'album de Quilapayún X Vietnam (Pour le Vietnam), et utilise aussi la chanson homonyme comme bande son. L'image d'ouverture affiche la légende suivante: "Chili 1969, 3000 jeunes marchent $200 \mathrm{~km}$ en dénonçant l'impérialisme ». Des images de la marche alternent avec des images réelles de la guerre. L'une des pancartes brandies par les étudiants porte un slogan particulièrement parlant: "Pour un art en faveur de la révolution ${ }^{36}$ ». De nombreux jeunes musiciens participent à cette mobilisation ${ }^{37}$. Elle représente peut-être, par son ampleur, le point culminant de la contestation contre l'interventionnisme nordaméricain au Vietnam.

\section{Allende et le Vietnam}

En 1970, un grand nombre d'artistes - dont les musiciens de la NCCh - s'investit à temps complet dans la campagne présidentielle du candidat de l'Unité populaire Salvador Allende. Cet engagement, qui portera ses fruits le 4 septembre de la même année avec l'élection du candidat de gauche, a pour corollaire immédiat le repli des musiciens engagés dans la problématique interne du pays. Par conséquent, hormis une chanson satirique anti-impérialiste reprise par Quilapayún («Tío Caimán » ${ }^{38}$ ), aucun autre enregistrement paru cette année-là ne fait mention du conflit au Vietnam. Quant à la musique savante, seule une œuvre fait exception: En Viet-nam, op. 10, cantate de chambre pour chœur, contralto, deux pianos et percussion sur un texte du poète Pablo Neruda, composée par Hernán Ramírez.

21 En matière de politique internationale, le programme du gouvernement d'Allende annonce l'établissement de relations avec « tous les pays du monde, indépendamment de leur position idéologique et politique [...] particulièrement avec ceux qui mènent des luttes de libération et d'indépendance ». La libre détermination des peuples est au cœur de la conception géopolitique de l'Unité populaire :

La défense acharnée de l'auto-détermination des peuples sera développée par le nouveau gouvernement comme condition de base pour la coexistence internationale. Par conséquent, sa politique sera vigilante et active dans la défense $\mathrm{du}$ principe de la non-intervention et pour refuser toute tentative de discrimination, de pression, d'invasion ou de blocage de la part des pays impérialistes ${ }^{39}$.

En accord avec ces principes, en mars 1971, le gouvernement d'Allende établit des relations diplomatiques au niveau des ambassades avec la $\mathrm{RDVN}^{40}$. Cet acte hautement symbolique est la concrétisation politique des engagements contractés avant l'élection du président socialiste. Le 6 février 1969, Allende, alors président du Sénat chilien, prononce un discours au Congrès où il souligne l'importance de la lutte vietnamienne, ainsi que sa signification pour les pays dits du tiers-monde :

...la lutte menée par ce peuple en Asie, agressé depuis cent ou mille ans, n'est pas seulement la bataille de ceux qui luttent en leur propre sein pour l'indépendance économique, mais l'expression du combat frontal contre l'impérialisme, qui doit retentir dans nos pays; nous rappelons que, sous une apparente liberté politique, nous sommes soumis à la tyrannie et à une brutale pression économique et que ladite liberté politique est une grande farce. C'est pourquoi il ne peut y avoir de frontières pour les pays en voie de développement dans cette lutte commune. La lutte du peuple vietnamien en est l'exemple. Les patriotes vietnamiens luttent pour 
eux-mêmes et aussi pour la liberté de tous les pays opprimés dans les différents continents $^{41}$. rencontre personnellement Ho Chi Minh. Cette visite à caractère officiel, où Allende exprimera le soutien solidaire du peuple chilien envers la cause vietnamienne, est considérée comme le premier pas vers l'établissement des relations diplomatiques entre les deux pays ${ }^{42}$.

\section{Les musiciens allendistes avec le Vietnam}

Au mois d'avril 1971, Víctor Jara publie l'un des disques les plus emblématiques de cette période : El derecho de vivir en $\mathrm{paz}^{43}$ (Le droit de vivre en paix). La chanson phare du même nom, une des créations les plus diffusées de son auteur, avait été composée pendant qu'il dirigeait Viet Rock. Pour l'enregistrement, Jara se fait accompagner par le groupe de rock Los Blops, « dans une expérience d' "invasion de l'invasion culturelle" ${ }^{44}$ ».

Un disque d'Isabel Parra, intitulé De aquí y de allá (D'ici et de là), paraît répondre à celui de Jara. À la chanson d'ouverture, destinée à encourager le peuple à travailler coude à coude avec le gouvernement populaire, fait suite un répertoire varié, incluant des créations propres, de sa mère Violeta, de Víctor Jara et d'auteurs de la Nueva Trova cubaine : Silvio Rodríguez et Pablo Milanés. De ce dernier, Isabel Parra chante notamment «Como en Vietnam » (Comme au Vietnam) ${ }^{45}$.

Quant au groupe Quilapayún, il fera une fois de plus une contribution importante avec la

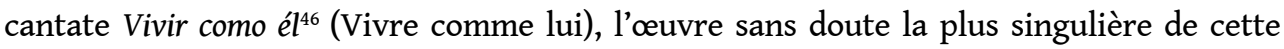
période. Elle est un hommage au héros du Vietcong, Nguyen Van Troi. Récitée, l'œuvre raconte les événements ayant eu lieu en 1964 : l'arrestation de Van Troi près de Saigon, au moment où le jeune résistant préparait un attentat contre Robert McNamara, le secrétaire américain d'État à la défense. Cet événement a eu un impact direct et une réponse inattendue en Amérique latine. En effet, au mois d'octobre, le lieutenant colonel de l'armée de l'air des États-Unis, Michael Smolen, était kidnappé au Venezuela par le FALN, qui menaçait de l'exécuter si Van Troi était fusillé au Vietnam. L'opération aboutit pourtant à un échec: alors que la prudence stratégique des autorités nord-américaines réussit à obtenir la libération de Smolen, Van Troi, après avoir subi la torture, sera exécuté quelques jours plus tard. La cantate Vivir como él cherche à préserver la mémoire de ces événements et ériger la figure de Van Troi en modèle, tout en mettant en évidence la félonie et la brutalité de l'envahisseur nord-américain. Sur le plan musical, il s'agit d'une œuvre composite, en raison de la juxtaposition des parties vocales écrites par le compositeur cubain Frank Fernández et des parties instrumentales du chilien Luis Advis ${ }^{47}$

27 L'extrême tension politique que vit le pays obligera définitivement les musiciens à orienter leur travail de création vers la contingence interne. Le combat pour le Vietnam ne pourra que s'éclipser en faveur des impératifs qu'impose la défense du gouvernement de l'Unité populaire. En effet, la chanson devient de plus en plus un instrument idéologique, fustigeant les boycotts successifs ainsi que les tentatives putschistes encouragées par la droite (et financées par les États-Unis). Après un premier soulèvement militaire étouffé en juin, ils renversent le gouvernement d'Allende par le biais d'un coup d'état, le 11 septembre 1973. Cette date marque la fin tragique de l'utopie de la «voie chilienne au socialisme » et le début d'une longue et sanglante dictature militaire. Les

Transposition, 4 | 2014 
artistes les plus en vue seront contraints à l'exil (Quilapayún, Sergio Ortega, les frères Parra...), d'autres, qui n'auront pas cette chance, subiront la torture, voire la mort (Víctor Jara, Jorge Peña Hen...).

\section{Les formes de la musique chilienne engagée contre la guerre}

L'examen de la production discographique étudiée montre l'existence d'un dénominateur commun : la double référence au Vietnam et à Cuba. Il est frappant en effet de constater que pratiquement aucun disque chantant la lutte du pays asiatique ne manquera de le faire aussi pour les révolutionnaires de l'île caribéenne. Comme le rappelle l'un des membres du groupe Quilapayún, il n'y a là pourtant rien de surprenant, car la Révolution cubaine et la Guerre du Vietnam auront compté parmi les événements les plus marquants pour la jeunesse contestataire chilienne des années 1960, qui se penche alors «du côté des audacieux révolutionnaires cubains et des héroïques vietnamiens ${ }^{48}$ ».

\section{Les paroles : une typologie}

De l'analyse des paroles des chansons contre la guerre se dégagent diverses orientations thématiques, qui nous permettent de proposer une classification, considérant les catégories suivantes : chansons (a) d'espoir et prémonition; (b) d'exaltation et mythification; (c) de dénonciation et accusation ; (d) de lamentation ; (e) et enfin, pacifistes.

a) Parmi les chansons qui véhiculent un sentiment d'espoir et de prémonition d'un meilleur futur, «Algún día, Vietnam » (Un jour, Vietnam) ${ }^{49}$ de Rolando Alarcón et « Por Vietnam » (Pour le Vietnam) de Quilapayún fournissent des exemples clairs. La première, en rythme de valse lente, accentuant le caractère de rêverie de la chanson, situe le récit à une époque où la guerre ne serait que le mauvais souvenir d'un temps révolu: «Un jour, Vietnam/tu pourras raconter au monde/ comment on a ôté la vie à ton peuple/ comment on a brûlé le visage de tes enfants/ Maintenant des souvenirs ${ }^{50}$ ». Le texte de Quilapayún, plus agressif, en même temps qu'il personnifie l'envahisseur nord-américain dans la figure d'un rapace, annonce sa prochaine défaite : «Aigle noir, bientôt tu tomberas/ le guérillero te vaincra ${ }^{51} »$. L'image des aigles noirs évoque d'ailleurs la redoutable force aérienne nord-américaine, symbole de sa puissance militaire : «Les aigles noirs viennent en volant/ avec leurs canons par-dessus la mer ${ }^{52}$ ». Les éléments musicaux jouent ici un rôle considérable dans la mise en scène sonore: alors que le sentiment de menace est efficacement souligné par l'insistance rythmique du rin, le message des paroles est mis en valeur par l'alternance des passages pour chant soliste, duo vocal et chœur à quatre voix.

b) Les textes d'exaltation et mythification sont caractéristiques de l'époque. De nombreuses chansons composées à cette période glorifient les martyrs des luttes ouvrières, les héros révolutionnaires ou les victimes de la répression. Deux chansons tirées du répertoire de la Nueva Trova cubaine et reprises respectivement par Rolando Alarcón et Isabel Parra appartiennent à cette catégorie. Alors que «Su nombre puede ponerse en verso » (Son nom peut être mis en vers), de Pablo Milanés, chante sur un rythme de guajira la triple dimension de Ho Chi Minh, président, poète et paysan, «Como en Vietnam » (Comme au Vietnam), composition du même auteur, vante les qualités humaines inégalables du peuple vietnamien, l'érigeant ainsi en exemple. 
c) Bien qu'en raison de son texte - écrit à la gloire du héros vietnamien Nguyen Van Troi -, la cantate «Vivir como él» (Vivre comme lui) ${ }^{53}$ de Frank Fernández et Luis Advis pourrait être classée dans la catégorie précédente, le ton de protestation violente qui s'en dégage la situe nettement dans la dénonciation et l'accusation :

Nguyen Van Troi,

tu as subi les tortures les plus horribles

mais les sbires n'ont pas réussi

à faire fléchir ta noble conviction,

Nguyen Van Troi

La dramaturgie de l'œuvre alterne chant et récitation, cette dernière passant du récit historique aux fragments qui font parler le protagoniste :

J'ai grandi formé par la révolution. Mon père était combattant de la résistance antifrançaise, et il a été torturé par l'ennemi au point de l'handicaper. Je porte en mon cœur une haine sans limites envers les ennemis de la patrie. Je suis arrivée à Saigon avec la ferme intention de continuer l'œuvre révolutionnaire de mon père [...] C'est parce que je n'ai pu supporter la mort de mon peuple et l'humiliation de ma patrie, que j'ai lutté contre l'impérialisme yankee.

L'œuvre finit par une déclaration d'engagement révolutionnaire :

Nguyen Van Troi

Pour le Vietnam nous sommes prêts à donner jusqu'à notre propre sang !

d) Une partie du répertoire véhicule l'idée de lamentation, comme la chanson « Hermano, hermano llorarás» d'Ewan MacColl. Reprise par Rolando Alarcón, elle n'est pas dépourvue d'un aspect religieux: " "Détruire, détruire le Vietnam"/ c'est l'hymne de l'envahisseur (...)/ Oh Christ, où est l'humilité ?/ Des frères se tuent sans pitié ${ }^{54} »$. Dans le style de la poésie populaire chilienne, la «Cueca por Vietnam» de Fernando González, également chantée par Alarcón, mélange lamentation et accusation :

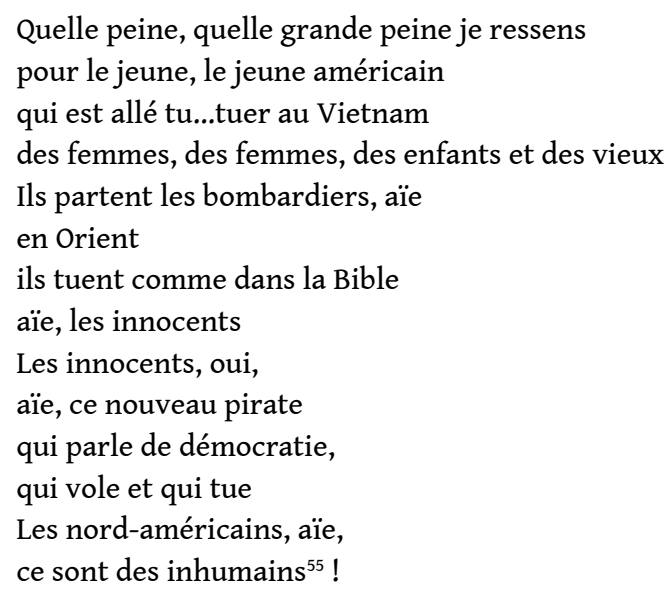

e) Au sein du versant pacifiste, on retrouve deux chansons d'Alarcón : « No juegues a ser soldado » (Ne joue pas à être soldat) et "La balada de Abraham Lincoln» (La ballade d'Abraham Lincoln). C'est un registre allusif que l'auteur utilise afin d'évoquer la guerre, soit en appelant à la conscience des soldats dans l'une, soit en mettant en évidence la trahison à la pensée de Lincoln dans l'autre. Mais ce sera une chanson de Víctor Jara qui marquera durablement les esprits, «El derecho de vivir en paz » (Le droit de vivre en paix) :

Le droit de vivre, poète Ho Chi Minh, 
toi qui frappes depuis le Vietnam

toute l'humanité,

aucun canon n'effacera

le sillon de tes rizières.

Le droit de vivre en paix.

L'Indochine est cet endroit

au-delà de la vaste mer

où l'on éclate la fleur

par génocide et napalm.

La lune est une explosion

il en jaillit une clameur.

Le droit de vivre en paix.

Oncle Ho, notre chanson

est un brasier de pur amour.

C'est la colombe du colombier,

c'est l'olive de l'olivier,

c'est le chant universel

la chaîne qui fera triompher

Le droit de vivre en paix ${ }^{56}$.

Rolando Alarcón, le chanteur qui a le plus contribué à la « cause ", est intéressante à bien des égards. Partant de la chanson pacifiste dans un style proche de la chanson de variété (ballade, go-go), il évolue par la suite vers une expression plus politisée en se rapprochant de la musique folk anglaise (notamment dans ses reprises de chansons d'Ewan MacColl), de la Nueva Trova cubaine et de la NCCh. Exception faite d'« El derecho de vivir en paz " de Víctor Jara, où l'innovation formelle est doublée par le croisement de la nouvelle chanson et du rock, la forme couplet-refrain est prédominante dans cette production ${ }^{58}$. Ajoutons enfin la composition de chansons sur des rythmes du folklore chilien : la cueca ( Cueca por Vietnam ») et le rin (« Por Vietnam»).

Située dans une catégorie intermédiaire, à la croisée de la musique populaire et de la musique savante, la cantate «Vivir como él » constitue un exemple clair de dépassement des genres. À cette œuvre, conçue à l'origine pour chœur par Frank Fernández et transcrite pour le groupe Quilapayún, Luis Advis ajoutera des interludes instrumentaux. Advis a résolu habilement le problème d'unification de l'œuvre, en conférant aux interludes une double fonction: ils servent à la fois de commentaires musicaux des récitatifs et de liens avec les parties vocales, grâce à l'utilisation de matériel motivique extrait et élaboré à partir de ces dernières ${ }^{59}$. Cette œuvre complexe et de longue haleine (20 min. environ) s'inscrit dans la lignée des cantates populaires qui voient le jour à cette époque-làa ${ }^{\circ}$, résultant d'une collaboration fructueuse entre musiciens populaires et 
savants. Ce type de composition opère - avec une certaine liberté - une réappropriation de la forme de la cantate baroque. Dans ces œuvres, le recitativo chanté est remplacé par la voix d'un récitant, jouant un rôle de narrateur - équivalent à celui de l'historicus dans l'oratorio -, alors que les parties instrumentales sont jouées par des instruments traditionnels latino-américains (parfois mélangés à des instruments européens). Ces œuvres préservent l'alternance entre arias, duos, chœurs, etc.

Comme nous l'avons vu, la Guerre du Vietnam n'a suscité que peu d'œuvres dans le domaine de la musique savante chilienne. Il est intéressant pourtant de souligner que les compositeurs de ces œuvres adhéraient tous à des principes technico-esthétiques associés aux avant-gardes post-weberniennes. Eduardo Maturana était l'un des représentants éminents du post-sérialisme local ${ }^{61}$. Hernán Ramírez a lui-même reconnu avoir employé la technique dodécaphonique dans sa cantate "anti-belliqueuse » En Viet-Nam ${ }^{62}$, œuvre qui ne sera malheureusement jamais créée. Quant à Gabriel Brncic - qui s'installait en 1965 en Argentine afin de poursuivre des études dans le CLAEM (Centre latino-américain des hautes études musicales) de l'Instituto Di Tella -, il était déjà un adepte de la musique électronique et de l'expérimentation en général ${ }^{63}$. En raison de leur double engagement, musical et politique, ces musiciens se rapprochaient de la ligne d'action plus radicale d'un Luigi Nono plutôt que des préceptes esthétiques bien connus du réalisme socialiste. Dans un entretien, Nono lui-même, qui visitait le Chili pour la deuxième fois en 1971 sur l'invitation du gouvernement de l'Unité populaire, semble donner son assentiment non seulement à la démarche des musiciens savants, mais à l'ensemble des musiques engagées chiliennes :

...La capacité de création [...] détruira complètement la distinction catégorielle que la classe bourgeoise a établie et diffusée, entre musique savante et musique populaire, musique classique et légère, de protestation et de consommation. [...] par conséquent, il n'y a pas de formes susceptibles d'être éliminées «a priori » par un stérile et rapide schématisme. Tout dépend du sens qu'elles peuvent acquérir dans le contexte d'une situation historique déterminée ${ }^{64}$.

41 Bien que la musique de Nono ne fût connue dans le pays qu'à travers des enregistrements, sa présence semble avoir fortement impressionné les musiciens chiliens qu'il rencontre lors de ses visites ${ }^{65}$, non seulement par ses connaissances profondes mais aussi par son engagement en faveur des peuples du tiers-monde, et tout particulièrement par sa solidarité avec les luttes du continent latino-américain. Outre ses écrits ${ }^{66}$, l'œuvre Como una ola de fuerza y luz (1971-1972) - dédiée à la mémoire du jeune militant du MIR Luciano Cruz - témoignera de l'impact de la deuxième visite de Nono au Chili. Après le coup d'état de septembre 1973, il rencontrera et collaborera avec des musiciens chiliens en exil ${ }^{67}$.

\section{Conclusion}

Intimement lié au mouvement social chilien des années 1960, le combat artistique contre la Guerre du Vietnam a été directement associé à des manifestations plus ou moins novatrices selon les cas dans le théâtre, la poésie, la peinture et les arts graphiques, le cinéma documentaire et la musique. Les œuvres suscitées par ce conflit armé font appel à des nouvelles formes d'expression artistique, jusqu'alors inédites dans le pays, telles que le muralisme des Brigades ${ }^{68}$ et le graphisme des pochettes de disques et d'affiches.

Dans le domaine musical, des échanges entre des musiciens de sphères différentes favorisent des croisements de genres, soit entre musique savante et musique populaire, 
soit entre sub-genres de la musique populaire. On observe d'ailleurs deux mouvements dans le corpus des chansons contre la guerre : la création d'un répertoire original et, dans une moindre mesure, l'appropriation d'un répertoire étranger. On constate également que l'inclusion du sujet vietnamien dans les répertoires coïncide avec la radicalisation politique des musiciens.

Bien que la répercussion sociale de la musique savante - malgré la valeur intrinsèque des œuvres- ait été moindre par rapport à la chanson, leur existence nominale indique une même volonté de la part du musicien de participer activement à la vie politique et aux luttes pour un meilleur avenir, en l'occurrence en faisant cause commune pour contester la guerre. Dans la sphère de la musique populaire, la mobilisation contre l'intervention nord-américaine constituera un élément identitaire qui différenciera le mouvement de la NCCh des autres courants de la chanson au Chili. L'impact du conflit sur ces musiciens contribue d'ailleurs à révéler les potentialités fonctionnelles de la chanson, celle-ci devenant un instrument efficace dans la transmission du message politique. Ceci sera largement exploité pendant la période de l'Unité populaire.

Le 30 avril 1975, l'entrée des révolutionnaires vietnamiens à Saigon marquera la fin de la Guerre du Vietnam. Les musiciens chiliens en exil, alors engagés dans la dénonciation de la dictature de Pinochet, salueront avec leurs chansons la victoire vietnamienne. Ainsi, une pièce instrumentale du groupe Inti-Illimani intitulée « Ciudad Ho Chi Minh » (Ho-ChiMinh-Ville), qui inclut des sons d'outils tels que le marteau et la scie, symbolisera la reconstruction de la grande ville rebaptisée du Sud-Vietnam ${ }^{69}$. Pour sa part Hugo Arévalo composera "La estrella de Vietnam» (L'étoile du Vietnam), où l'évocation du peuple héroïque - toujours incarné par la figure de Ho - s'unit à la nostalgie du Chili et à l'espoir de sa prochaine libération du joug militaire. Cette réaffirmation des engagements passés au milieu des adversités de l'exil confirme - s'il en était encore besoin - qu'au Chili, comme ailleurs, la Guerre du Vietnam aura été bien plus qu'un « bruit lointain ».

\section{BIBLIOGRAPHIE}

AHARONIAN, Coriún, « Carlos Vega y la teoría de la música popular. Un enfoque latinoamericano en un ensayo pionero », in Revista Musical Chilena, № 188, juillet-décembre 1997, p. 61-74.

ALEXANDER, Leni, « Luigi Nono 1924-1990 », in Revista Musical Chilena, N 173, janvier-juin 1990, p. 118-119.

ALTEN, Michèle, « Le Chant du Monde : une firme discographique au service du progressisme (1945-1980) », in ILCEA, N 16, 2012. Consulté le 19 octobre 2012. [http://ilcea.revues.org/ index1411.html]

AMORÓS, Mario, « Salvador Allende ante el mundo », in Tareas, $\mathrm{N}^{\circ} 130$, septembre-décembre 2008, p. 85-105.

ARAYA, Pedro, «El Mercurio miente (1967) : siete notas sobre escrituras expuestas », in Revista Austral de Ciencias Sociales, $\mathrm{N}^{\circ} 14,2008$, p. 157-172. 
BARRAZA, Fernando, La Nueva Canción Chilena, Santiago, Quimantú, 1972.

BESSIERE, Bernard, La nouvelle chanson chilienne en exil, Plan-de-la-Tour, Éditions d'aujourd'hui, 1980.

BODENHOFER, Andreas, VILA, Cirilo, « Entrevista a Luigi Nono », in Revista Musical Chilena, Nº 115-116, juillet-décembre 1971, p. 3-9.

CARRASCO, Eduardo, Quilapayún : la revolución y las estrellas, Santiago, RIL, 2002.

CLOUZET, Jean, La nouvelle chanson chilienne, Paris, Seghers, 1975.

COMITÉ CHILENO DE SOLIDARIDAD CON VIETNAM, Fuera yanquis de Vietnam! Al pueblo de Chile. Llamamiento!, 1966.

CONTRERAS, Carlos, Intervención norteamericana en Vietnam. Discurso del H. Senador señor Carlos Contreras L. Diario de sesiones del Senado. Publicación oficial. Legislatura extraordinaria. Sesión 33a, 7 de abril de 1965.

« Embajada de Chile en la República Socialista de Vietnam. Relaciones bilaterales », in site internet du Ministère des Relations extérieures du Chili. Consulté le 3 août 2012 [http:// chileabroad.gov.cl/vietnam/relacion-bilateral/relaciones-bilaterales/]

FERMANDOIS, Joaquín, « Chile y la Guerra de Vietnam. Ruido a la distancia », article de presse in La Tercera, 23 avril 2000. Consulté le 29 juillet 2012 [http://www7.uc.cl/historia/cinfo/Articulos/ fermandois4.htm]

GARCÍA, Fernando, « Discusión sobre la música chilena » [fragment sur Neruda et la musique chilienne], in Araucaria, № 2, 1978.

GARCÍA, Fernando, « Recordando a Luigi Nono », in Revista Musical Chilena, ㅜ 173, janvier-juin 1990, p. 120-121.

GONZÁLEZ, Juan Pablo et alii, Historia social de la música en Chile, 1950-1970, Santiago, Ediciones UC, 2009.

HERRERA, Silvia, « Eduardo Maturana : un compositor del siglo XX », in Revista Musical Chilena, ${ }^{\circ}$ 199, janvier-juin 2003, p. 7-38.

HERRERA, Silvia, « Gabriel Brncic. Un primer acercamiento hacia el maestro y compositor en el exilio », in Revista Musical Chilena, N² 204, juillet-décembre 2005, p. 26-59.

JARA, Joan, Víctor, un canto inconcluso, Santiago, LOM, 2007.

"LACMA installs its monumental Matta », in Los Angeles Times, 15 mai 2009. Consulté le 10 novembre 2012 [http://latimesblogs.latimes.com/culturemonster/2009/05/m.html]

MATTELART, Armand, Los medios de comunicación de masas. La ideología de la prensa liberal en Chile,

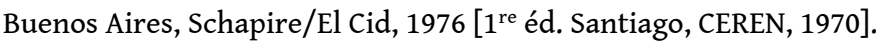

« Murales de David Alfaro Siqueiros y Xavier Guerrero (de la Escuela México de Chillán) », in site internet du Conseil des monuments nationaux du Chili. Consulté le 10 juin 2013 [http:// www.monumentos.cl/OpenSupport_Monumento/asp/PopUpFicha/ficha_publica.asp? monumento=1829]

NERUDA, Pablo, Las manos del día, Buenos Aires, Losada, 1968 [4édition 1975].

NERUDA, Pablo, Fin de mundo, Buenos Aires, Losada, 1969 [4édition 1976].

NERUDA, Pablo, Incitación al nixonicidio y alabanza de la revolución chilena, Santiago, Quimantú, 1973. 
NERUDA, Pablo, « Avec l'Académie, oui, avec l'impérialisme, non », in Né pour naître, traduit de l'espagnol par Claude Couffon, Paris, Gallimard, 1978, p. 386-389.

NONO, Luigi, Écrits, traduit de l'italien et de l'allemand par Laurent Feneyrou, Genève, Contrechamps, 2007.

PARADA-LILLO, Rodolfo, « La Nueva Canción Chilena 1960-1970 : Arte y política, tradición y modernidad ", in Patrimonio Cultural, $\mathrm{N}^{\circ}$ 49, printemps 2008, p. 17-20.

PARRA, Nicanor, «Palabras obscenas », in Revista Chilena de Literatura, N 1, automne 1970, p. 79-85.

PENNETIER, Claude, « Magny, Colette », in Le Maitron. Dictionnaire biographique, mouvement ouvrier, mouvement social. Consulté le 25 janvier 2013 [http://maitron-en-ligne.univ-paris1.fr/spip.php? article140558]

Programa básico de gobierno de la Unidad Popular. Candidatura presidencial de Salvador Allende, Santiago, [s.n.], 1970.

RAMIREZ, Hernán, « Reflexiones », in Revista Musical Chilena, № 133, janvier-mars 1976, p. 47-59. Revue Punto Final, Nº 8, janvier 1966.

ROKHA, Pablo (de), Idioma del mundo, Santiago, Multitud, 1958.

SALAZAR, Gabriel et alii, Historia contemporánea de Chile V, Santiago, LOM, 2002.

SANTANDER, Ignacio, Quilapayún, Madrid, Ediciones Júcar, 1984.

SAUL, Ernesto, Pintura social en Chile, Santiago, Quimantú, 1972.

SCHUMACHER, Federico, "Catálogo de las obras electroacústicas de Gustavo Becerra-Schmidt », in Revista Musical Chilena, $\mathrm{N}^{\circ}$ 207, janvier-juin 2007, p. 81-84.

TANGOL, Nicasio (éd.), Vietnam heroico, Santiago, Imp. Horizonte, 1967.

TORRES, Rodrigo, « Luigi Nono », in Revista Musical Chilena, N 173, janvier-juin 1990, p. 122-123.

VEGA, Carlos, « Mesomúsica. Un ensayo sobre la música de todos », in Revista Musical Chilena, N

• 188, juillet-décembre 1997, p. 75-96.

\section{Discographie}

ADVIS, Luis, FERNANDEZ, Frank, Vivir como él. Quilapayún. Jota-Jota JJL-12, « Vivir como él », 1971.

ALARCON, Rolando, La balada de Abraham Lincoln, No juegues a ser soldado. Rolando Alarcón et le groupe Los Tickets. EMI Odeón chilena, LDC 36632, « El nuevo Rolando Alarcón », 1967.

ALARCON, Rolando, Algún día Vietnam, Las doradas colinas de Binh Thuân. Rolando Alarcón. Tiempo, VBP-286, « Por Cuba y Vietnam », 1969.

CARRASCO, Eduardo [musique], GOMEZ ROGERS, Jaime [paroles], X Vietnam. Quilapayún. JotaJota, JJL-01, « X Vietnam », 1968 ; Idem, Für Vietnam. Quilapayún. ETERNA, 815 058, « 3. Festival des Politischen Liedes », 1972 [enregistrement en direct].

GONZALEZ, Fernando, Cueca por Vietnam. Rolando Alarcón. Tiempo, VBP-286, « Por Cuba y Vietnam », 1969.

JARA, Víctor, El derecho de vivir en paz. Víctor Jara et le groupe Los Blops. DICAP, JJL-11, « El derecho de vivir en paz », 1971. 
MACCOLL, Ewan, Hermano, hermano...llorarás. Rolando Alarcón. Tiempo, VBP-286, « Por Cuba y

Vietnam », 1969.

MACCOLL, Ewan, La balada de Ho Chi Minh. Rolando Alarcón. Tiempo-Astral, VBP-264, « El mundo folklórico de Rolando Alarcón », 1969.

MILANES, Pablo [musique], PITA RODRIGUEZ, Félix [paroles], Su nombre puede ponerse en verso. Rolando Alarcón. Tiempo, VBP-286, « Por Cuba y Vietnam », 1969.

PARRA, Ángel, El banquerito. Ángel Parra. DICAP, DCP-3, « Canciones funcionales/ Ángel Parra interpreta a Atahualpa Yupanqui », 1969.

SEVES, José, Ciudad Ho Chi Minh. Inti-Illimani. Dischi dello Zodiaco, VPA 8265, « Hacia la libertad », 1975.

\section{Documentaires}

MUEL, Bruno, Septembre chilien, [Groupes Medvedkine] France, 1973, 39 min.

RAMIREZ, Álvaro, SAPIAIN, Claudio, Por Viet Nam, [Centro de alumnos del Instituto Pedagógico. Universidad de Chile] Chili, 1969, 3 min.

\section{Entretiens}

Entretien avec le compositeur Patricio Wang, Paris, 25 juillet 2012.

Échanges via e-mail avec le muraliste Eduardo « Mono » Carrasco, Italie-France, janvier 2014.

\section{NOTES}

1. Dans cet article, nous distinguons trois notions loin d'être équivalentes pour toutes les traditions musicologiques ni même transposables à toutes les langues : celles de musique savante, musique populaire et musique folklorique. Bien que de nombreux transferts entre ces différents univers se produisent, puisqu'il ne s'agit nullement de catégories monolithiques, mais au contraire poreuses et interdépendantes, nous entendrons ici par musique savante («música culta », « música docta » ou «música de tradición escrita », pour la musicologie chilienne), la musique composée par des musiciens ayant suivi une formation académique européanisée (harmonie, contrepoint, fugue, analyse, orchestration, etc.) et de longue durée auprès de maîtres ou dans des institutions destinées à ces fins (conservatoires, écoles de musique, etc.). Ces musiciens visent à produire des œuvres d'un haut degré de complexité technique et formelle. En revanche, le terme musique populaire recouvre pour nous un vaste univers comprenant les manifestations musicales urbaines, développées par des musiciens autodidactes ou n'ayant pas forcement reçu une formation musicale académique. Elle se manifeste par la création d'œuvres se servant de formes simples, le plus souvent la chanson. La musique folklorique, quant à elle, fait référence à l'ensemble des musiques traditionnelles métisses, dont la transmission est éminemment orale. Précisons cependant que certaines musiques évoquées dans cet article présentent des difficultés évidentes de classification. En effet, les trois univers musicaux précédemment évoqués peuvent être représentés côte à côte à l'intérieur d'une même production discographique (notamment dans certains disques du groupe Quilapayún), ou se présenter sous des formes hybrides dans une même œuvre (mélange folklorique/populaire dans des chansons «d'inspiration folklorique»; métissage populaire/savant dans des "cantates 
populaires", etc.). La période que nous abordons ici voit ces catégories s'éroder considérablement, par l'action des musiciens qui remettent en question la dichotomie savant/ populaire. Enfin, en raison de sa résonance auprès de la musicologie latino-américaine - même si elle peut sembler quelque peu datée de nos jours -, mentionnons ici l'intéressante notion de "mesomúsica» (mésomusique) - musique du milieu, située entre la musique savante et le folklore, mais distincte de celles-là - proposée par le musicologue argentin VEGA, Carlos, «Mesomúsica. Un ensayo sobre la música de todos », in Revista Musical Chilena, No 188, juilletdécembre 1997, p. 75-96 [Il s'agit du texte d'une conférence donnée à Bloomington en avril 1965, lors de la Second Inter-American Conference on Musicology]. La définition de "mésomúsica » a été acceptée par Philip Tagg en 1991, au moment où il présidait le conseil éditorial de l'Encyclopedia of Popular Music of the World (EPMOW) : «Le concept de 'musique populaire' de la EPMOW est similaire à celui de 'mesomúsica' de Vega ». Voir AHARONIAN, Coriún, "Carlos Vega y la teoría de la música popular. Un enfoque latinoamericano en un ensayo pionero », in Revista Musical Chilena, íbid., p. 61-74. L'auteur y discute les nuances et problèmes présentés par cette notion.

2. Ce terme semble avoir été consacré par Ricardo García, journaliste et l'un des principaux promoteurs de cette mouvance artistique dans le milieu musical chilien, vers la fin des années 1960. Ce sera le Primer Festival de la Nueva Canción Chilena effectué à Santiago en 1969 - et organisé par García -, qui établira définitivement cette appellation. Bien que la littérature sur la NCCh soit vaste, nous pouvons signaler les ouvrages pionniers de BARRAZA, Fernando, La Nueva Canción Chilena, Santiago, Quimantú, 1972, et CLOUZET, Jean, La nouvelle chanson chilienne, Paris, Seghers, 1975.

3. Bien entendu, cela n'est pas l'apanage des musiciens chiliens. Ainsi, pour ne citer que des exemples plus proches du lecteur français, signalons la production musicale de chanteuses engagées telles que Francesca Solleville (voir les disques Et je t'appelle et Poèmes vietnamiens chantés par Francesca Solleville) et Colette Magny (voir notamment son 33 tours Vietnam 67), où la double référence cubaine et vietnamienne est également présente. Une étude comparative détaillée pourrait montrer des similitudes frappantes entre leurs démarches (choix du répertoire et stratégies de diffusion) et celles des musiciens chiliens abordés dans cet article. Ces convergences expliquent en partie leur rapprochement sur la scène européenne, au moment où ces derniers s'exilent après le coup d'état du général Pinochet en septembre 1973.

4. Au Chili, cet engagement s'exprime par un art qui s'interroge sur son rôle social et s'élève contre la gratuité de la création artistique bourgeoise, en repensant son identité latinoaméricaine. Comme nous le montrerons dans cet article, c'est le poète Pablo Neruda - l'homme et l'œuvre - qui en fournira le modèle.

5. SALAZAR, Gabriel et alii, Historia Contemporánea de Chile V, Santiago, LOM, 2002, p. 131.

6. Ibid., p. 132.

7. Intervención norteamericana en Vietnam. Discurso del H. Senador señor Carlos Contreras L. Diario de sesiones del Senado. Publicación oficial. Legislatura extraordinaria. Sesión 33a, 7 de abril de 1965.

8. Fuera yanquis de Vietnam! Al pueblo de Chile. Llamamiento!, Comité chileno de solidaridad con Vietnam, 1966.

9. RODRÍGUEZ ELIZONDO, José, « Lo que ví en Vietnam », Punto Final, N 8, janvier 1966, p. 3-24. Le même numéro de la revue, dans l'article d'ouverture, rendait compte des diverses activités menées par trois organismes, la Commission chilienne de solidarité avec les peuples d'Asie et d'Afrique, la Commission chilienne de solidarité avec le Vietnam du sud et le Mouvement des partisans pour la Paix, en collaboration avec la CUT (Centrale unique des travailleurs) et la Fédération minière, voir Comisión chilena de solidaridad con los pueblos de Asia y África, « Intensificar la solidaridad de masas con la lucha del pueblo vietnamita », in id., p. 1. 
10. Le FLN est le sigle du Front national de libération du Sud-Vietnam, connu également comme Vietcong. La RDVN est la République démocratique du Vietnam (Nord-Vietnam).

11. GONZÁLEZ, Juan Pablo et alii, Historia social de la Música Popular en Chile, 1950-1970, Santiago, Ediciones UC, 2009, p. 29.

12. Voir «LACMA installs its monumental Matta » [en ligne], in Los Angeles Times, 15 mai 2009. Consulté le 10 décembre 2012.

13. TANGOL, Nicasio (éd.), Vietnam heroico, Santiago, Imp. Horizonte, 1967, p. 9 : « ...el pueblo vietnamita no está luchando solamente en contra del imperialismo norteamericano; su lucha implica la libre determinación de los pueblos, el respeto a los países pequeños y a la dignidad de todos los seres humanos cualquiera que sea el color de su piel. Su victoria será la victoria de los pueblos oprimidos por la burguesía imperialista internacional. Será el fin de la esclavitud económica en que vive toda la América Latina y abrirá las puertas para que la humanidad camine en libertad, en paz y dignidad. ». Note : sauf indication contraire, toutes les traductions sont nôtres.

14. Voir de ROKHA, Pablo, Idioma del mundo, Santiago, Multitud, 1958.

15. PARRA, Nicanor, «Palabras obscenas », in Revista Chilena de Literatura, $\mathrm{N}^{\circ} 1$, automne 1970, p. 81.

16. GARCÍA, Fernando, «Discusión sobre la música chilena », in Araucaria, Nº 2, 1978, p. 138. «La figura militante del poeta ayudó a muchos de los músicos chilenos a comprender cuál es el papel que el creador debe jugar en nuestro continente en un momento en que se agudiza la lucha antiimperialista ».

17. Citons notamment : NERUDA, Pablo, Las manos del día, Buenos Aires, Losada, 1968 ; Idem, Fin de mundo, Buenos Aires, Losada, 1969 ; Idem, Incitación al nixonicidio y alabanza de la revolución chilena, Santiago, Quimantú, 1973.

18. Voir NERUDA, Pablo, "Avec l'Académie, oui, avec l'impérialisme, non ", in Né pour naître, traduit de l'espagnol par Claude Couffon, Paris, Gallimard, 1980, p. 386-389.

19. Dédicace originale en espagnol : «A la memoria de los caídos en la Guerra de Vietnam ». Cette œuvre a été créée le 31 mai 1965 par Hanns Stein et Galvarino Mendoza, dans le théâtre Antonio Varas à Santiago du Chili. Voir HERRERA, Silvia, «Eduardo Maturana: un compositor del siglo XX », in Revista Musical Chilena, № 199, janvier-juin 2003, p. 36.

20. Malheureusement, il n'y a pas d'enregistrements disponibles de ces œuvres, que nous connaissons grâce aux catalogues établis par la musicologue HERRERA, Silvia, "Eduardo Maturana... », art. cit.; Idem, "Gabriel Brncic. Un primer acercamiento hacia el maestro y compositor en el exilio », in Revista Musical Chilena, $\mathrm{N}^{\circ}$ 204, juillet-décembre 2005, p. 53.

21. La date de composition est incertaine (1965/1966 ca.).

22. "Desde el fondo del pueblo ha surgido/una voz de justicia social/ Son los pobres del mundo que avanzan/como ejemplo tienen a Vietnam". Note : Malgré leur permanence parfois éphémère sur la toile, nous renvoyons le lecteur aux liens youtube. Voir Hymne du MIR : http://youtu.be/ jT0mApfKGRk?t=40m57s

23. ALARCON, Rolando, La balada de Abraham Lincoln, No juegues a ser soldado. Rolando Alarcón et le groupe Los Tickets. EMI Odeón chilena, LDC 36632, «El nuevo Rolando Alarcón ». Voir http:// youtu.be/v6omWCgeF9I [démarrer à 20'37"pour «La balada...» et à 28'27" pour «No juegues... »].

24. Jota Jota évoque au Chili les Jeunesses communistes (JJCC).

25. GONZÁLEZ, Juan Pablo et alii, op. cit., p. 110.

26. CARRASCO, Eduardo [musique], GOMEZ ROGERS, Jaime [paroles], X Vietnam. Quilapayún. JotaJota, JJL-01, « X Vietnam ».

27. Le rin est un rythme originaire du sud du Chili, spécifiquement de l'île de Chiloé. En $2 / 4$ et tempo rapide, la base rythmique du rin est composée de quatre demi-croches suivies de deux croches, dont la deuxième est accentuée. 
28. «Yanki, yanki, yanki/ cuidado, cuidado/ (...) Águila negra ya caerás », voir http://youtu.be/ HbG5SeBZNMA. Une version en direct de cette chanson paraîtra plus tard dans un disque édité à l'issue du 3. Festival des Politischen Liedes, qui a eut lieu à Berlin-Est en février 1972.

29. CARRASCO, Eduardo, Quilapayún: la revolución y las estrellas, Santiago, RIL, 2003, p. 131-132.

30. Sur le réseau complexe d'influences des capitaux étrangers sur les médias de masse au Chili de l'époque, voir MATTELART, Armand, Los medios de comunicación de masas. La ideología de la prensa liberal en Chile, Buenos Aires, Schapire/El Cid, 1976 [1 $1^{\mathrm{e}}$ éd. Santiago, CEREN, 1970].

31. «Está sufriendo el banquero/ qué penitas llevará/ ¿Será Vietnam, será Biafra/ lo que lo hace llorar?», in PARRA, Ángel, El banquerito. Ángel Parra. DICAP, DCP-3, «Canciones funcionales. Ángel Parra interpreta a Atahualpa Yupanqui », voir http://youtu.be/mifvecGPES0?t=7m15s.

32. MACCOLL, Ewan, Hermano, hermano...llorarás. Rolando Alarcón. Tiempo, VBP-286, « Por Cuba y Vietnam ».

33. JARA, Joan, Victor un canto inconcluso, p. 141-142. "La autora no sobrepasa un primitivo pacifismo norteamericano. No ve al imperialismo de su país con los ojos con que lo vemos los chilenos y latinoamericanos [...] La posición que yo he tomado ante esta obra es la del juicio y la condena al imperialismo. Nosotros no somos norteamericanos y no tenemos por qué incurrir en las distorsiones de la autora. Hay norteamericanos aparentemente progresistas que no pueden liberarse de su visión torcida -y en el fondo imperialista- del tercer mundo. »

34. Je remercie Eduardo "Mono" Carrasco, muraliste et fondateur des Brigades Ramona Parra, de son aide dans la vérification de certains éléments avancés lors de la dernière révision de cet article.

35. Voir ARAYA, Pedro, «El Mercurio miente (1967): Siete notas sobre escrituras expuestas ", in Revista Austral de Ciencias Sociales, $\mathrm{N}^{\circ}$ 14, 2008, p. 163-165. Selon le témoignage d'Eduardo "Mono" Carrasco, il s'agissait d'un groupe de sept hommes qui, sur une jeep datant de la Seconde Guerre mondiale, était chargé de mener les actions. La conception picturale des interventions n'était alors qu'embryonnaire, le message politique direct l'emportant sur toute conception artistique. Eduardo « Mono » Carrasco, communication personnelle, 18 janvier 2014.

36. Voir http://www.youtube.com/watch?v=h2TABfo1Zsw

37. Entretien avec Patricio Wang, Paris, 25 juillet 2012.

38. "Tío Caimán » (Oncle Caïman) est une chanson du Panaméen Carlos Francisco Chang Marín (1922-2012). L'Oncle Caïman est l'équivalent de l'Oncle Sam, personnification des États-Unis. Voir http://youtu.be/EWdeMgaJazA.

39. Programa básico de gobierno de la Unidad Popular. Candidatura presidencial de Salvador Allende, 1969, p. 32. «La defensa decidida de la autodeterminación de los pueblos será impulsada por el nuevo Gobierno como condición básica de la convivencia internacional. En consecuencia su política será vigilante y activa para defender el principio de no intervención y para rechazar todo intento de discriminación, presión, invasión o bloqueo intentado por los países imperialistas ».

40. Voir «Embajada de Chile en la República Socialista de Vietnam. Relaciones bilaterales », in site internet du Ministère des Relations extérieures du Chili : http://chileabroad.gov.cl/vietnam/ relacion-bilateral/relaciones-bilaterales/ Consulté le 3 août 2012.

41. Voir AMORÓs, Mario, "Salvador Allende ante el mundo", in Tareas, № 130, septembredécembre 2008, p. 91-92. "...la lucha librada en Asia por ese pueblo, centenaria o milenariamente agredido, no es sólo la batalla de quienes pelean en su propio seno por su independencia económica, sino la expresión del combate frontal contra el imperialismo, que debe repercutir en nuestros países; hemos señalado que, si bien aparentemente tenemos libertad política, estamos sometidos a la tiranía y a una brutal presión económica y que dicha libertad política es una gran farsa. Por tal motivo, no puede haber fronteras para los países en vías de desarrollo en esta lucha común. El heroísmo del pueblo vietnamita es un ejemplo de ello. Los patriotas vietnamitas luchan por ellos mismos y también por la libertad de todos los países oprimidos en los distintos continentes". 
42. « Embajada de Chile en la República Socialista de Vietnam... », doc. cit.

43. JARA, Víctor, El derecho de vivir en paz. Víctor Jara et le groupe Los Blops. DICAP, JJL-11, «El derecho de vivir en paz ", voir http://youtu.be/-zMvRkwcnaA.

44. JARA, Joan, Víctor, un canto inconcluso, Santiago, LOM, 2007, p. 162.

45. MILANES, Pablo, Como en Vietnam. Isabel Parra. DICAP, DCP-27, «De aquí y de allá », voir http://youtu.be/oGNlru6WfDs?t=23m4s.

46. ADVIS, Luis, FERNANDEZ, Frank, Vivir como él. Quilapayún. Jota-Jota JJL-12, «Vivir como él », voir http://youtu.be/62uhUEs8xfA

47. SANTANDER, Ignacio, Quilapayún, Madrid, Ediciones Júcar, p. 70.

48. PARADA-LILLO, Rodolfo, «La Nueva Canción Chilena 1960-1970: Arte y política, tradición y modernidad ", in Revista Patrimonio Cultural, N 49, printemps 2008, p. 17.

49. ALARCON, Rolando, Algún día, Vietnam. Rolando Alarcón. Tiempo, VBP-286, «Por Cuba y Vietnam ».

50. «Algún día, Vietnam,/ podrás contar al mundo/ cómo cegaron la vida de tu pueblo,/ cómo quemaron el rostro de tus niños,/ que ahora son recuerdos ». Voir ALARCON, Rolando, Algún día Vietnam. Rolando Alarcón. Tiempo, VBP-286, «Por Cuba y Vietnam ».

51. «Águila negra ya caerás/ el guerrillero te vencerá ».

52. «Las águilas negras vienen volando/ con sus cañones por sobre el mar ».

53. Dans le disque du même nom et en accord avec la tendance à associer la lutte du Vietnam à celle de Cuba, cette cantate est suivie d'un extrait musicalisé de la « Seconde déclaration de La Havane ", discours prononcé par Fidel Castro le 4 février 1962.

54. “'Destruir, destruir Vietnam'/ es himno del invasor (...)/ Oh, Cristo ¿Dónde está la humildad?/ Hermanos se matan sin piedad".

55. "Qué pena, qué pena más grande siento/ del joven, del joven americano/ que fue a ma..., que fue a matar al Vietnam/ mujeres, mujeres, niños y ancianos/ Qué pena, qué pena más grande siento./ Parten los bombarderos, caramba/ y en el Oriente/ caramba, matan como en la Biblia/ caramba, a los inocentes./ Los inocentes, sí,/ caramba, nuevo pirata/ que habla de democracia,/ que roba y que mata./ ¡Los norteamericanos, caramba, son inhumanos!”.

56. JARA, Víctor, « El derecho de vivir en paz », trad. française in Jean Clouzet, La nouvelle chanson chilienne, op. cit., p. 173-174. Traduction modifiée. Hormis quelques variantes dans la scansion métrique, les paroles originales de cette chanson comportent 3 strophes composées de 6 heptasyllabes plus un ennéasyllabe : «El derecho de vivir/ poète Ho Chi Minh,/ que golpea de Vietnam/ a toda la humanidad./ Ningún cañon borrará/ el surco de tu arrozal./ El derecho de vivir en paz.// Indochina es el lugar/ más allá del ancho mar,/ donde revientan la flor/ con genocidio y napalm./ La luna es una explosión/ que funde todo el clamor./ El derecho de vivir en paz.// Tío Ho, nuestra canción/ es fuego de puro amor,/ es palomo, palomar,/ olivo del olivar,/ es el canto universal/ cadena que hará triunfar/ el derecho de vivir en paz. »

57. Cette chanson sera utilisée dans le documentaire de MUEL, Bruno et alii, Septembre chilien, [Groupes Medvedkine], France, 1973, $39 \mathrm{~min}$.

58. Sur ce point, seul Víctor Jara semble porter un regard novateur sur le genre, avec «El derecho de vivir en paz » (dans sa version discographique enregistrée avec le groupe de rock «Los Blops» en 1971). Cette chanson comporte une période de 32 mesures, servant non seulement de support au texte, mais aussi à l'improvisation instrumentale. Chaque répétition de la période (sept au total) opère une intensification graduelle par le biais d'un enrichissement sonore, tant par l'augmentation du volume que par le niveau d'activité des instruments.

59. L'œuvre est structurée autour de 4 récitatifs parlés (dont le dernier est scindé en 2 parties), suivis d'interludes instrumentaux et de pièces pour chœur masculin. À un premier récitatif (dont le texte est le seul à la troisième personne) présentant l'argument de l'œuvre, suit un interlude instrumental; il s'agit d'une sorte de commentaire musical qui évolue par la suite vers une pièce à part entière. La section suivante (chœur 1) s'ouvre sur un motif de 3 notes (quarte descendante 
sol dièse-ré dièse, puis seconde mineure ascendante ré dièse-mi) anticipée par une quena et reprise par le chœur bocca chiusa, sur lequel se développe le chant d'un soliste, les cordes (guitares, tiple et charango) ne faisant que souligner discrètement certains passages. Dans la section centrale de ce chœur, le nom de «Nguyen Van Troi » est chanté sur des agrégats extrêmement tendus harmoniquement. Le deuxième récitatif - désormais à la première personne - fait parler le protagoniste. Le deuxième interlude présente un développement accru et une subtile imbrication motivique ; cette section finit par l'introduction du motif initial de la partie chorale suivante ( $\mathrm{A}$ pesar del sufrimiento cantamos... »/« Malgré la souffrance nous chantons... »). Cette section voit l'écriture chorale se déplier à partir de l'unisson vers des agrégats complexes. Après une brève intervention du narrateur (récitatif 3), le quatrième morceau choral s'ouvre sur un passage marqué par une pédale vocale et des homorythmies, pour ensuite reprendre le développement harmonique du deuxième morceau choral. Ensuite, l'interlude instrumental 3 présente une reprise variée de la partie centrale du premier interlude. Après le quatrième récitatif, le morceau choral 4 - véritable climax de l'œuvre - alterne des passages contrapuntiques, à l'unisson et homorythmiques/homophoniques. Le nom de « Nguyen Van Troi » y apparaît à nouveau revêtu d'une grande tension harmonique, alors qu'une écriture imitative serrée chante « Hay que darle muerte al invasor... »/ «Il faut tuer l'envahisseur... ». Un fade out des voix (réalisé en studio) cède la place à la dernière intervention du récitant $(4 b)$, et un fade in réintroduit le chœur. Après une dernière reprise des agrégats vocaux sur le nom de Van Troi, le chœur prononce à l'unisson et en crié-chanté la consigne finale: «Por Vietnam estamos dispuestos a dar hasta nuestra propia sangre »/《Pour le Vietnam, nous sommes prêts à donner jusqu'à notre propre sang » (le mot «sang " y étant le seul chanté). En raison de la variété de ressources techniques employées, ainsi que par le traitement harmonique complexe, cette œuvre dépasse largement le champ de la chanson, se rapprochant ainsi de la musique contemporaine.

60. L'exemple paradigmatique de ce genre est la Cantate Santa María de Iquique, composée par Luis Advis et enregistrée par Quilapayún en 1970.

61. Après Por la justicia y la paz déjà évoquée, Maturana composera encore une œuvre d'orientation ouvertement politique: Responso para el guerrillero (1968), pour orchestre symphonique et bande magnétique, œuvre dédiée "A la memoria del Comandante 'Che' Guevara " (À la mémoire du Commandant 'Che' Guevara). HERRERA, Silvia, «Eduardo Maturana... », art. cit., p. 37.

62. RAMIREZ, Hernán, « Reflexiones », in Revista Musical Chilena, $\mathrm{N}^{\circ} 133$, janvier-mars 1976, p. 48.

63. Pour une étude détaillée sur ce compositeur, voir HERRERA, Silvia, «Gabriel Brncic. Un primer acercamiento hacia el compositor y maestro chileno en el exilio », art. cit.

64. BODENHOFER, Andreas, VILA, Cirilo, « Entrevista a Luigi Nono ", in Revista Musical Chilena, ${ }^{\circ}$ 115-116, juillet-décembre 1971, p. 6: «...la capacidad de creación [...] va a destruir completamente la distinción categorial que la clase burguesa ha establecido y fomentado, entre música culta y música popular, música clásica y ligera, de protesta y de consumo [...] En consecuencia, no hay formas susceptibles de ser eliminadas 'a priori', todo depende del sentido que puedan adquirir en el contexto de una determinada situación histórica ".

65. Voir notamment les témoignages posthumes sur Luigi Nono de la compositrice Leni Alexander, du compositeur Fernando García et du musicologue Rodrigo Torres, in Revista Musical Chilena, No 173, janvier-juin 1990, p. 118-123. Voir également l'entretien de Sofía Asunción Claro à Nuria Schoenberg-Nono, in Revista Musical Chilena, $\mathrm{N}^{\circ}$ 206, juillet-décembre 2006, p. 84-91.

66. Divers écrits de Luigi Nono rendent compte de ses liens avec les milieux politiques, intellectuels et musicaux du Chili. Voir notamment «In memoriam Luciano Cruz » [inédit du vivant du compositeur], in NONO, Luigi, Écrits, Genève, Contrechamps, 2007, p. 362-364; «Le chant de Víctor Jara ", ibid., p. 379-382. Sur la dernière visite de Nono au Chili en 1983, au moment du début de l'ouverture progressive des frontières du Chili en pleine dictature de 
Pinochet, voir « Salut aux travailleurs de la culture du Chili », ibid., p. 507-510 et le témoignage de Rodrigo Torres dans la Revista Musical Chilena No 173 cité précédemment.

67. Ainsi, par exemple, Nono a assuré la régie du son de la partie électroacoustique de la cantate Corvalán du compositeur chilien Gustavo Becerra-Schmidt, créée en 1975 à la Biennale de Venise, voir SCHUMACHER, Federico, "Catálogo de las obras electroacústicas de Gustavo BecerraSchmidt ", in Revista Musical Chilena, № 207, janvier-juin 2007, p. 83.

68. Bien que l'art des Brigades compte au moins deux autres sources importantes (celles du peintre français Fernand Léger et de l'affiche cubaine des années 1960), le muralisme au Chili trouve un précédent direct dans le muralisme mexicain. En effet, David Alfaro Siqueiros et Xavier Guerrero se rendent au Chili entre 1941-1942 afin de réaliser des œuvres dans l'Escuela México, école construite et offerte à la ville de Chillán (située au sud du pays) par le gouvernement mexicain, après le tremblement de terre qui avait détruit cette localité. Siqueiros y peint notamment une œuvre monumentale : « Muerte al invasor». Voir le site internet du Conseil des monuments nationaux: http://www.monumentos.cl/OpenSupport_Monumento/asp/ PopUpFicha/ficha_publica.asp?monumento=1829. Si les œuvres des muralistes mexicains influencent incontestablement l'iconographie latino-américaniste déployée par les brigades chiliennes, ces dernières s'en distinguent par l'utilisation de couleurs vives et pures, de gros contours bien définis, peints à la broche et non au pinceau. Il s'agit d'un art d'extérieur, urbain, de propagande politique directe. L'un des principaux apports de l'art des brigades a peut-être été son caractère collectif, où la notion d'auteur tend à s'estomper en faveur d'une création groupale excluant tout individualisme. « Les fresques murales urbaines sont anonymes et passagères. Leur essence réside en ce qu'elles ne perdurent pas. Leur message change au fur et à mesure des événements. Elles sont tellement mêlées avec la vie qu'elles sont en conflit permanent avec le vent, la pluie, et le travail d'autres hommes. Ce qu'on peint aujourd'hui sera détruit demain ", voir Ernesto Saúl, Pintura social en Chile, Santiago, Quimantú, 1972.

69. BESSIERE, Bernard, La Nouvelle chanson chilienne en exil, Plan-de-la-Tour, Éditions d'aujourd'hui, 1980, p. 279.

\section{RÉSUMÉS}

Ni les États-Unis ni l'Europe n'ont l'apanage de la contestation contre la Guerre du Vietnam. Les peuples du tiers-monde en ont fait, pendant une dizaine d'années, le symbole de la lutte antiimpérialiste. Au Chili, la jeunesse engagée se solidarise avec le peuple vietnamien, dont le combat face à l'envahisseur nord-américain est considéré comme héroïque et exemplaire dans la défense du droit à l'auto-détermination. Les artistes, et tout particulièrement les musiciens, expriment alors le rejet de cette guerre à travers leurs œuvres, la chanson étant l'un des véhicules privilégiés du message politique. Structuré en deux parties, cet article retrace d'abord le devenir de cette contestation, en mettant l'accent sur l'articulation entre contexte politique et création artistique durant une période clé de l'histoire du Chili. Il examine ensuite les diverses formes que prend la musique engagée de l'époque afin d'en dégager une typologie.

The opposition to the Vietnam War is not an isolated phenomenon of America or Europe. In fact, during a decade, this war embodies the symbol of the anti-imperialism resistance by the peoples of the third world. In Chile, the politically committed youth supports the Vietnamese people. They consider the battle against the American invader to be heroic and an example of the 
warfare towards the right of self-determination. The artists, and musicians in particular, express their opposition to war through artistic works: the canción is then established as the favored vehicle for delivering the political message. This paper is structured into two sections. It first describes the process of the protest, emphasizing the articulation between the political context and the artistic creation during a key period of Chile's history. Later, it examines the different forms of the politically committed music of that time to establish a typology.

\section{INDEX}

Mots-clés : Chili, nouvelle chanson chilienne, Unité populaire, Guerre du Vietnam, contestation, anti-impérialisme, musique et politique

Keywords : Chile, Chilean nueva canción, Unidad Popular, Vietnam War, protest, antiimperialism, music and politics

\section{AUTEUR}

\section{MAURICIO GÓMEZ GÁLVEZ}

Mauricio Gómez Gálvez est doctorant en musicologie à l'Université Paris-Sorbonne. Après des études d'interprétation musicale et de pédagogie de la musique au Chili, il obtient un master en musique et musicologie à l'Université Paris-Sorbonne (mémoire sur les écrits de René Leibowitz dans la revue Les Temps Modernes). Il prépare actuellement une thèse sur les formes d'appropriation de la musique savante européenne chez les compositeurs chiliens du second $\mathrm{xx}^{\mathrm{e}}$ siècle, sous la direction de Michèle Alten d'abord, puis de Jean-Marc Chouvel. 